\title{
THE PERCEPTIONS OF TRADITIONAL HEALERS OF CERVICAL CANCER CARE AT GA MOTHAPO VILLAGE IN LIMPOPO PROVINCE
}

\author{
Matsheta Mokgadi Sophy \\ University of Pretoria, South Africa \\ Mulaudzi Fhumulani Mavis \\ North West University, South Africa \\ mavis.mulaudzi@nwu.ac.za
}

\begin{abstract}
The purpose of this article is to explore and describe the perceptions of traditional healers of cervical cancer care. The incidence of cervical cancer, especially among black South African females, is among the highest in the world. Women report at clinics and hospitals on a daily basis with advanced stages (stages III and IV) of cervical cancer. Black women consult traditional healers first, before they consult health-care professionals. Although cervical cancer survival rates are said to be improving across South Africa, not all women benefit from the screening programme for early detection of cervical cancer. Traditional healers perform an indispensable role in the delivery of health care, especially in rural areas where access to biomedical care is limited. The article is based on a qualitative, descriptive, and exploratory study. The study population included traditional healers who were chosen through snowball sampling. Data was collected by means of in-depth interviews. Data was analysed using Tesch's method. The findings of this study demonstrated that the traditional health practitioners have good knowledge about cervical cancer care. This was shown by the knowledge they had of naming the disease, predisposing factors and causes, of cancer care, symptoms of diseases, diagnostic measures and methods of treatment. The findings of this study provided valuable information on the perceptions of traditional healers of cervical cancer care. In view of the knowledge that the traditional healers possess, this study recommended that there be sharing of knowledge and collaboration between modern health-care practitioners and traditional healers. Collaboration may assist in early detection and treatment of cervical cancer, thereby improving the mortality rate.
\end{abstract}

Keywords: Traditional healers, traditional medicine, western medicine, cervical cancer, perceptions.

\section{INTRODUCTION}

Cancer of the cervix is a major public-health problem worldwide. According to Averette and Janicek (2001: 93), 400000 new cases of cervical cancer are diagnosed worldwide every year, $80 \%$ of them in developing countries. At least 200000 women die of cervical cancer annually. The incidence of and mortality 
from cervical cancer are second only to breast cancer, and in parts of the developing world cervical cancer is the primary cause of death in women of childbearing age. According to Peltzer (2001: 12), the incidence of cervical cancer, especially among black South African females, is among the highest in the world. Women report at clinics and hospitals on a daily basis with advanced stages (stages III and IV) of cervical cancer rendering cure or control impossible (Walker, Michelow \& Walker 2002: 45). Its complexity is aggravated by the factors such as late-stage diagnosis, lack of timely services, lack of appropriate medical care, travelling distance to preventive and treatment service, individual tribal behavioural contingencies, inequalities in health status, barriers in women's health care and missed opportunities for screening (Becker, Alfonso \& Beard, 2006: 28). Black women consult traditional healers first, before they consult health-care professionals. Most women diagnosed with cancer of the cervix have never had a papinocolaous (Pap smear). Mulaudzi (2003: 23) argues that in rural areas factors such as low socio-economic status, inaccessibility of health facilities, lack of transport and rampant poverty, discourage early diagnosis of diseases. Recognition of cultural and ethnic influences is considered important in the early detection of cervical cancer. Traditional healers view cancer as curable and treatment depends on the location of cancer (Steyn \& Muller, 2000: 6).

There is a growing global interest in the use of traditional medicine to treat ailments, including diseases like cancer; hence $80 \%$ of people living in Africa today receive medical care from traditional healers (Mulaudzi, 2003: 23, Tshabalala-Msimang, 2004: 6-17). In Zambia, Ndubane and Höjer (1999: 15) have found that traditional healers operate close to the people and are indispensable health-care providers in many rural communities where modern medicine is not readily available. According to Downey, Cody, McCloskey, Wilson, Arnott, Lister and Slevin (1994: 86-89), another reason for the increased popularity and current success of traditional healing may be the failure of science and medicine to produce curative treatment for commonly occurring types of cancer and other incurable diseases such as AIDS and multiple sclerosis.

In general, the earlier cancer is diagnosed, the better the chances of controlling or curing it (Brown, 1992: 490). Steyn and Muller (2000: 8) maintain that involving or incorporating traditional healers in cervical cancer care would help control the incidence of cervical cancer and the mortality rate because they have knowledge and skills in this regard. In addition, the prevailing shortage of westernised health-care providers and facilities necessitates considering the assistance of traditional health practitioners. Bringing them within the primary-health fold would therefore help to curb shortage and assist health care professionals to render quality care. Traditional healers are often the first and last line of defense against the most contagious and debilitating diseases that plague the lives of African people. Although western medicine is generally accepted throughout Africa, it has not replaced but rather augmented indigenous health approaches. There is growing realization that it is possible for traditional and western practitioners to work together to improve patients' wellbeing (Mulaudzi 2001: 14; TshabalalaMsimang, 2004: 6-17; Peu, Troskie \& Hattingh, 2001: 57). The purpose of this 
article is to explore and describe the perceptions of traditional healers of cervical cancer care and their treatment modalities.

\section{LITERATURE REVIEW}

The traditional health-care system has provided care to people for decades, even before the western health care system could be integrated into traditional cultures. Mulaudzi (2003: 23) and Tshabalala-Msimang (2004: 6-17) state that a large proportion of the population relies heavily on traditional practitioners and medicinal plants to meet their health needs. Ndubane and Höjer (1999: 15) concur with the above authors by emphasising that traditional healers operate close to the people and are indispensable health-care providers in many rural communities where modern medicine is not readily available. Clients find them user-friendly, accessible and affordable.

Traditional medicine continues to play a significant role in the treatment and management of life-threatening diseases and traditional healers are custodians of indigenous knowledge. Traditional healers are respected and trusted in the community because of their expertise in rendering holistic care (Peu, Troskie \& Hattingh, 2001: 57; Campbell, 1998: 4; Mulaudzi, 2003: 23). Traditional healers are known to use only natural substances and have a sound knowledge of the medicinal properties of indigenous plants (Campbell, 1998: 1). Moreover, indigenous healers have expertise in treating and curing diseases such as epilepsy, diabetes and other chronic conditions without subjecting patients to daily intakes of chronic medication as is common practice in modern medicine (Mulaudzi, 2003: 23; Jones, 1999: 1807).

Cancer patients opt out of conventional medical treatment to consult traditional healers. Black people believe that a disease must be cured not controlled (Mulaudzi 2001: 15). In turn in modern medicine, there are chronic diseases which are not considered curable but can be controlled for example diabetes, epilepsy and hypertension. Understanding the sociocultural dimension of a patient's health beliefs is critical to a successful clinical encounter It is therefore not suprising to see that after been diagnosed of cancer and undergoing radiation therapy which comes with side effects that may delay healing, black patients still seek assistance from traditional healer whom they believe will have herbs which will cure the disease. Vilakazi (2006: 2) argues that although it is well known that $80 \%$ of black patients visit traditional healers before visiting the medical doctor there are no records available to show how many people are seen or cured by traditional healers as it is not documented or proven scientifically. He therefore asserts that traditional medicine is proven by what he termed walking evidence. Campbell (1998:4) concur with the above authours by stating that traditional healers are precious resources for the dissemination of basic health care, especially in rural areas where access to information is limited. They may serve as a backbone of dissemination information on screening thus assisting in early detection of cancer of the cervix. 


\section{RESEARCH DESIGN AND METHODS}

An explorative, descriptive and contextual design within a qualitative paradigm was used to conduct the study. This design was chosen because qualitative research is a holistic approach that allows informants to describe their real-life experiences, while the researcher attached meanings to their descriptions.

The population for the research was sampled from traditional healers of the Bapedi ethnic group at Ga-Mothapo area. Ga Mothapo is a rural village situated in the Capricorn District, Limpopo Province, about $40 \mathrm{~km}$ from Polokwane city. The inhabitants of $\mathrm{Ga}$ Mothapo belong to different ethnic groups such as Tsonga, Venda, Ndebele and Pedi, the dominant ethnic group. The traditional healers of Ga-Mothapo were chosen because they are known to be involved in the treatment and care of clients suffering from cervical cancer, and people of Ga-Mothapo are among the few groups that still value and honour traditional practices. Snowball or network sampling, which is the selection of participants by means of referrals from earlier participants, was used (Polit \& Hungler, 2001: 246). This sampling technique is used when it is difficult to find participants with information. The researcher identified one traditional healer who was known to treat and care for patients with cervical cancer, who later referred her to other known healers. The sample size was determined by saturation of data (the repetition of discovered information and confirmation of previously collected data) (Streubert \& Carpenter, 1999: 22).

Eight (8) traditional healers were interviewed in their own homes, and saturation of data was reached by the sixth participant. Unstructured interviews which provided in-depth information about the phenomenon were conducted with four (4) female and four (4) male traditional healers. The researcher posed the following question:

What is your perception of cervical cancer care?

It was the duty of the researcher to probe for more information after asking this question, while encouraging the participant to talk freely (Parahoo 1997: 52). A tape recorder was used to record the interviews and field notes were made immediately about the participants' responses to questions and observations to ensure richness of the data. The interviews were conducted in Sepedi and later translated into English for wider readability and understandability. The independent coder and the supervisor assisted with the transcribing and analysing of data.

\section{MEASURES TO ENSURE TRUSTWORTHINESS}

For this study, the method of ensuring trustworthiness in the evaluation of data quality as described by Lincoln and Guba (in Polit \& Hungler, 2001: 426) was used. Credibility strategy was increased by means of prolonged engagement where an extended period of time was spent with the participants. Field notes for each interview were kept for auditability (Krefting, 1991: 218). Triangulation of methods of data collection was done as the researcher used interviews, observation and field notes to collect the richest possible data. Literature control was 
conducted to compare and verify the findings with various sources. In ensuring confirmability, the researcher read the transcripts to the participants to confirm whether what was written accurately reflected their experiences. The researcher bracketed her ideas about the traditional healers' perceptions of cervical cancer care and maintained a neutral stance during interviews. An independent coder was used in the analysis, as well as the researcher's supervisor, who evaluated the results. In order to make the findings transferable and applicable to other settings, participants with various experiences were chosen to increase the possibility of shedding light on the research question from a variety of aspects (Graneheim \& Lundman, 2004: 109; Mayan, 2001: 10). To ensure dependability, data collection, analysis and interpretation of data were thoroughly described. to indicate how repeatable and auditable the study might be (Richter \& Peu, 2004: 35).

\section{Ethical considerations}

Ethical considerations are important, as reproductive health such as cervical cancer is considered a private and confidential matter. The principles of research ethics and code of ethics were always honoured. Participants were respected and treated with dignity, like autonomous agents, and were also given the opportunity to make informed voluntary decisions (Polit \& Hungler 2004: 15, Brink 2000: 39). Permission to conduct the study was requested in writing from the Limpopo Province Ethics Committee as well as from Mothapo Head Kraal.

\section{DATA ANALYSIS}

In qualitative research, data collection and data analysis occur simultaneously, and the data is usually in the form of written words or videotapes, audiotapes and photographs. Data analysis therefore involved the examination of words and not numbers. The interview transcripts and field notes were systematically organised until they were understood in such a way that the research question was addressed (Bailey, 1997: 137). The researcher listened to the recorded interviews frequently and repeatedly read through the verbatim transcripts. Data were analysed in the language in which the interviews were conducted and Tesch's method of qualitative research was used (De Vos, 2001: 271; Creswell, 2003: 192; Richter \& Peu, 2004: 33).

Themes and sub-categories were noted as they emerged from the analysis. The researcher and the coder coded independently and the coder, who is an experienced researcher, also used Tesch's method to analyse the transcribed interviews. The researcher and the coder discussed and reached consensus on the findings. The data were grouped into five main categories and their subcategories. Comprehensive themes were developed to support the subcategories. The findings were discussed with the participants at the end of the study, and they were asked to comment on the data and interpretations to ensure that the researcher had captured the participants' own words and meanings (Polit \& Hungler, 2004: 444; Krefting, 1991: 219).

\section{Discussion of findings}

The findings of the study revealed that traditional healers of Ga Mothapo, like other societies with different cultural behaviours have their own beliefs and 
practices of how to name, prevent, diagnose and treat diseases including cancer of the cervix. Campbell (1998: 1) advances the view that traditional healers have a deep knowledge of diseases and the medicinal properties of indigenous plants.

\section{Naming of the diseases}

The first category that came out of the findings was "Naming of the disease". The participants indicated that naming of the disease was done according to the description of the character of the disease. For example, terms used to describe cervical cancer were "sesepidi" (something that moves), and "tlhagala" (to be worn out). The following quotations relate to this finding:

"Cancer is a Western name, we call it sesepedi." "In our culture we call it sesepedi." "We call it thagala in Sesotho".

These terms appear to be the same as identified by Steyn and Muller (2000: 5) in their study of "Traditional healers and cancer prevention". This naming of the disease "sesepidi" corresponds with the patho-physiology of biomedicine that spreads (metastasise) to other organs if not treated in time (Otto, 2001: 18, Ignatavious \& Workman, 2002: 412). "TIhagala", in turn, refers to a necrosed tissue of the tumour mass leading to offensive per vaginal discharge (Christensen \& Kockrow, 2003: 524).

Traditional healers 's naming of disease usually corresponds either with causes or signs and symptoms of the disease. Janes (1999: 804) states that traditional medicines are transferred from culturally specific methods for identifying, naming and treating illness. In this case the naming of the disease is related to the fact that cancer of the cervix is perceived as a complex type of disease that develops over time from a precursor lesion. The progression is slow and it may take as long as ten to twenty years before the disease becomes invasive. .(Pillay, 2002: 104, Ross \& Wilson, 2001: 455, Berek \& Hacker, 2000: 345).

\section{Predisposing factors and causes of cervical cancer}

In certain cultures, the occurrence of cancer is attributed to insufficient use of herbal medicine, an insult to an ancestor or a perceived punishment (Giger \& Davidhizar, 1998: 118). The traditional healers of Ga-Mothapo area attributed cancer to excessive smoking, too many sexual partners, poor diet, early sexual intercourse, sexually transmitted infections and heredity. The finding was supported by the following statements:

"This disease occurs when a woman has multiple partners (Ge mosadi a kitima le sekwata sa banna)"; "Too many partners and STIs are the main cause, because sekgalaka (STIs) are transmitted from one partner to another, as men do not have uteruses, they cannot be victims of cervical cancer."

Otto (2000: 248) and Allanach and Gangar (2001: 216) are of the opinion that as with many cancers, the exact aetiology of cancer of the cervix remains unknown. They further suggest several associated risk factors such as multiple partners, 
early sexual intercourse and childbearing, STIs, HIV/AIDS, smoking and oral contraceptives. The above statement is supported by Peltzer (2001: 13), Averette and Janicek (2001: 93), and Miaskowski (1999: 11) when they add human papilloma virus and grand multipara as risk factors for cervical cancer. Walboomers, Jacobs, Manos, Bosch, Kummer and Shah (1999: 12-19) maintain that cervical cancer is a sexually transmitted disease, pointing out that one or more oncogenic types of human papilloma virus (HPV) are found in over $99 \%$ of cases.

\section{Symptoms of the disease}

The characteristic symptoms of cervical cancer as perceived by traditional healers include abdominal pains, burning, foul-smelling vaginal discharges, per vaginal bleeding, painful coitus, dysuria and swelling.

"The uterus starts to develop a growth like polyps, which causes the patient to feel more pain." "The patient usually complains of lower abdominal pains, burning on mensturation." "Some patients will suffer with incontinence of urine."

Most of the burning or pain experienced by individuals with cancer originates from the tumour and is related to pathology. Invasive procedures, toxicities of treatment, infection and physical limitation, and nerve involvement leads to severe pain (Yarbro, Frogge \& Goodman, 1999: 120; Potter \& Perry, 2001: 1288; Allanach \& Gangar, 2001: 220). As the disease progresses, pain can be experienced as a dragging sensation in the abdomen or the lower back (Allanach \& Gangar, 2001: 220). On palpation the cervix is firm and usually expanded (Berek \& Hacker, 2000: 346).

The anatomical position of the bladder, so closely adjacent to the cervix, favours contagious spread from the cervix to the bladder (Kufe, Pollock, Weicheselbaum, Bast, Holland, and Frei III, 2003: 1788). The spread of the disease into the bladder could lead to urinary symptoms such as frequency, burning of micturition (BOM) and haematuria (Allanach \& Gangar, 2001: 220; Ignatavicius \& Workman, 2002: 1774). These are signs of recurrence or metastasis (spread) of the disease in the later stage (Ignatavicius \& Workman, 2002: 1774). Patients with advanced disease may present with haematuria or incontinence, suggesting direct extension of the tumour to the bladder (Kufe et al., 2003: 1788).

\section{Foul smelling vaginal discharge}

This was one of the characteristic symptoms identified. The participants viewed foul vaginal discharge as dirt coming out of the vagina and too much vaginal bleeding. The participants described offensive vaginal discharge and vaginal bleeding as signs and symptoms of cervical cancer. The findings are supported by the following statements:

"When the tumour is ripe, it starts to release pus or discharge per vagina, which is offensive." "The patient will complain of unusual offensive vaginal discharge and excessive vaginal bleeding." 
Early symptoms of cervical cancer can include vaginal bleeding or discharge and are often associated with vaginal douching and sexual intercourse (Stanhope \& Lancaster, 2000: 568). Offensive vaginal discharge is the second most common symptom. Bleeding often occurs after coitus or after menopause (Christensen \& Kockrow, 2003: 524; Allanach \& Gangar, 2001: 220). Bleeding is very slight at first, but as the disease progresses, the bleeding increases. The vaginal exudates become watery, then increase and become dark and bloody with an offensive odour caused by necrosis (death of tissue) and infection of the tumour mass (Christensen \& Kockrow, 2003: 524). Gynaecological cancer occurs in $20 \%$ to $40 \%$ of women who experience post-menopausal bleeding (Ignatavicius \& Workman, 2002: 1754). Brown (1992: 492) is of the opinion that bleeding between menstrual periods or after the menopause must always be investigated, as it is not normal.

\section{Diagnostic measures}

In modern medicine, Pap smears and cervical biopsies are among the diagnostic methods used to assess and diagnose cervical cancer (Neal \& Hoskin, 2003: 136). Similarly, traditional healers have their own way of diagnosing disease, such as throwing of bones, observation and history-taking.

"When she enters my room I just feel heat in my stomach, as if I am burning inside". "My bones will show sesepedi". "Throwing of the bones will confirm the diagnosis." "Throwing the bones will show me the type of illness you are suffering from".

Throwing of bones appears to precede the taking of history and physical examination (Okpak, 1999: 482; Campbell, 1998: 56; Shai-Mahoko, 1996: 32; Steyn \& Muller, 2000: 4; Allanach \& Gangar, 2001: 221; Ndubane \& Höjer, 1999: 22; Steyn \& Muller, 2000: 6).

\section{Prevention and Treatment}

In biomedicine, cervical cancer is treated with radiotherapy, chemotherapy and surgery (Ignatavicius \& Workman, 2002: 1771). Treatment is based on the stages of the disease assessed by examination under local anaesthesia, the histopathology of the tumour and the radiological findings together with the general fitness, health and preference of the patient. Traditional healers, however, use different types of herbs (traditional medicines). The treatment depends on the knowledge and capability of the traditional healer, as well as the willingness of the ancestors.

The aim of traditional treatment is to extract and pull the disease out, to the outside, that is, to have the cancer (sesepedi) come out of the uterus to the outside, to be treated and cured. Similarly, in biomedicine, treatment is given to cure the disease, but if this cannot be guaranteed, it is also to contain the disease (keep it under control). When cancer is advanced, treatment can be given to relieve symptomatic pain (Brown, 1992: 493). The purpose of traditional 
treatment is not only to cure the disease, but also to heal the patient (Makgopa, 2001: 373), that is, the healing of both body and spirit (Campbell, 1998: 7).

The participants' general methods included oral (per mouth), steaming, inhalation, incision and application. Traditional clothing or fabrics as well as dance and music were used in the healing ceremonies. Some of these methods are similar to those used in biomedicine, for example, chemotherapy (oral), incision (surgery) and radiotherapy were found to be exceptional.

Campbell (1998: 5) and Ndubane and Höjer (1999: 22) indicate that the application of herbs depends largely on the type of disease, but generally most are either taken orally, inhaled in steam/smoke, or applied to the affected area. Roots and bark are the dominant plant parts used in herbal preparations (Ndubane \& Höjer, 1999: 22). Steyn and Muller (2000: 6) state that traditional healers are guided by their ancestors (badimo) when throwing the bones or in dreams with regard to the type of herbs to use and mix. Traditional medicine is mostly used throughout the cancer trajectory to aid recovery and prevent recurrence (Xu, Towers, Li \& Collet, 2006: 397). Xu et al. (2006: 397) add that traditional medicine is healing-orientated, focusing on activating the natural reserves and rebuilding the body's resistance, so the effect is long-term rather than transient. Otto (2001: 256) refers to long-term therapy in biomedicine where a follow-up with cervical cytology, colposcopy, and pelvic examination at 3-monthly intervals for the first year, every 6 months for the next 3 years and then annually, beginning five years after treatment, is recommended for early detection of recurrent invasive cervical cancer.

Steyn and Muller (2000: 8) and Christensen and Kockrow (2003: 716) emphasise the importance of preventing STIs and avoiding early sexual activity and multiple sexual partners, detecting cancer early through observing warning signs, seeking advice early, and cultivating self-control. Christensen and Kockrow (2003: 526) further stress the importance of reinforcing correct information and providing factual information to correct any misconceptions.

\section{CONCLUSIONS}

The study confirmed that traditional healers have knowledge of cervical cancer care, and have developed culturally appropriate terms to communicate with their clients.

The traditional healers' way of naming diseases signify their knowledge of the aetiology and patho-physiology of cancer of cervix. The participants referred to cervical cancer as thagala, seso or sesepedi, which means that tissues in the affected area are worn out and something (the sore) moves or spreads from one place to another. In Western medicine, this is called metastasis of cancer tumours. T/hagala or sesepedi was described as a tumour or sore that develops slowly, grows bigger then becomes painful, later bleeds and does not heal easily. All the participants perceived cancer of the cervix as a troublesome disease that was difficult to deal with. The complexity of the disease was aggravated by the fact that treatment needed to be given for a long time. 
The perception of causes and symptoms as viewed by traditional healers is more or less similar to the causes and symptoms as known and learned in modern medicine. According to the participants, early engagement in sexual intercourse, casual sexual relationships, STIs and smoking caused cervical cancer. In other words, this was the result of a transgression of moral rules or lack of selfcontrol/respect, and acculturation to modern Western norms and values. The participants did not believe in witchcraft as the cause of diseases such as cervical cancer.

The diagnostic measures used by traditional healers were appropriate and well described. Diagnosis was done through throwing the bones, history- taking and observation. Western medicine uses Pap smears, cervical biopsies, historytaking and observation, which are similar. The participants' knowledge of the signs and symptoms facilitated the process of diagnosis. From the findings it is clear that traditional healers maintain a strong belief in the power of the ancestors. The study revealed that traditional healers use techniques similar to those used by Western healers, for example psychoanalysis (dream analysis), $x$-rays and scans (bone throwing).

The study found that although traditional healers seem able to cure cervical cancer, they have no strategy to detect cancer while still in the asymptomatic stage. It is clear that traditional healers play a part in the prevention of cancer, as they give their clients information on cervical cancer whenever they consult. Traditional healers are respected and trusted by the community because of their expertise in rendering holistic care. The involvement of the family was viewed as important for proper family history, support and enhancement of the healing process (that is, the rendering of holistic patient care). These findings are significant, particularly considering the extent of cervical cancer in the country and the shortage of material and human resources. Traditional healers are precious resources for the provision of basic health care, especially in rural areas such as Ga-Mothapo where access to resources is limited.

\section{RECOMMENDATIONS}

From the findings, it is clear that traditional healers play a relevant and indispensable role in cervical cancer care. The knowledge that traditional healers have with regard to naming, causes, symptoms and diagnostic measures of cancer of the cervix should be taken into consideration as an essential component of developing effective health education programmes in Limpopo Province, especially in Ga-Mothapo and other rural areas.

Health-care providers should have an understanding of the cultural beliefs and practices that affect traditional healers' treatment of cervical cancer. Healers in both fields should be trained to understand each other's mode of care, in order to share knowledge and skills. Professional health-care providers should be culturally sensitive to and aware of the indispensable role of the ancestors in traditional healing and care. 
Mutual referral and collaboration should be promoted between the two healthcare systems. Further studies should be conducted in larger areas, both rural and urban, in all the provinces of the country. This would promote better understanding and provide richer information, which could then be incorporated into the syllabus. This would benefit practice and training. 


\section{REFERENCES}

Allanach, V. and Gangar, E.A. (2001). Gynaecological nursing: a practical guide. London: Churchill Livingstone.

Andrews, M.M. and Boyle, J.S. (1999). Transcultural concepts in nursing care. Philadelphia: Lippincott.

Averette, H.E. and Janicek, M.E. (2001). Cervical cancer: prevention, diagnosis and therapeutics. A Cancer Journal for Clinicians, 51(2): 92-107.

Bailey, D.M. (1997). Research for health professionals: a practical guide. (2nd ed). Philadelphia: Davis.

Becker, S.A., Alfonso, D.D. and Beard, M.B. (2006). Talking circle: Northern American Indian women's views of cancer as a health issue. Public Health Nursing, 23(1): 27-36.

Berek, J. and Hacker, N. (2000). Practical gynaecologic oncology. Philadelphia: Lippincott.

Brink, H.I. (2000). Fundamentals of research methodology for health care professionals. (2nd ed). Cape Town: Juta.

Brown, L. (1992). Manual of family health. London: Royal College of Nursing.

Burkhardt, M. (2000). Healing relationships with nature. Complementary Therapies in Nursing and Midwifery, 6: 35-40.

Campbell, S.S. (1998). Called to heal: traditional healing meets modern medicine in Southern Africa today. Johannesburg: Zebra Press.

Christensen, B.L. and Kockrow, E.O. (2003). Adult health nursing. (4th ed). St Louis: Mosby.

Creswell, J.W. (2003). Research design: Qualitative and quantitative approaches. London: Sage.

De Vos, A.S. (2001). Research at grassroots: for the social science and human service professionals. Pretoria: Van Schaik.

Downey, S.M., Cody, M.M., McCloskey, P., Wilson, P.D., Arnott, L, Lister, T.A. and Slevin, L. (1994). Pursuit and practice of complementary therapies by cancer patients receiving conventional treatment. BMJ 309: 86-89 (9 July).

Giger, J.N. and Davidhizer, R.T. (1998). Transcultural nursing: assessment and intervention. St Louis: Mosby.

Graneheim, U.H. and Lundman, B. (2004). Qualitative content analysis in nursing research: concepts, procedures and measures to achieve trustworthiness. Nurse Educator Today, 24: 105-112.

Ignatavicius, D.D. and Workman, M.L. (2002). Medical surgical nursing: critical thinking for collaborative care. (4th ed). Philadelphia: Saunders. 
Jones, G.R. (1999). The health transition, global modernity and the crisis of tradition: the Tibetan case. Social Science \& Medicine, 48: 1803-1820.

Krefting, L. (1991). Rigor in qualitative research: the assessment of trustworthiness. American Journal of Occupational Therapy, 45(3): 214-222.

Kufe, D.W., Pollock, R.E., Weicheselbaum, R.R., Bast, R.C., Holland, J.F. and Frei III, E. (2003). Cancer management, Pediatric Oncology, Complications Informatics. Cancer Medicine Vol 2. London, Hamilton.

Makgopa, M. (2001). Indigenous healing system: an oral transmission. Building on the indigenous - An African perspective, National Research Foundation, S.A.51-51

Mayan, M.J. (2001). An introduction to qualitative methods: a training module for students and professionals. Alberta: International Institute for Qualitative Methodology.

Miaskowiski, C. (1999). Oncology Nursing. An essential guide. USA: Sage.

Mulaudzi, F.M. (2003). A tribute to traditional healers. Nursing Update, 27(10): 22-24.

Mulaudzi, F.M. (2001). Synergy between indigenous knowledge, modern health c are and scientific research: a challenge in the 21st century: Rau Health/Gesondheid vol 6 no 4: 14-20

Nagel Kerk, J.S. (2001). Diagnostic reasoning: case analysis in primary care practice. Philadelphia: Saunders.

Ndubane, P. and Höjer, B. (1999). Traditional healers and the treatment of sexually transmitted illness in rural Zambia. Journal of Ethno Pharmacology, 67: 15-25.

Neal, A.J. and Hoskin, P.J. (2003). Clinical oncology: basic principles and practice. (3rd ed). London: Oxford University Press.

Okpak, D.T. (1999). Traditional African medicine: theory and pharmacology explored. Tips- Dec. View Point 20: 482-485.

Otto, S. (2000). Oncology nursing. (4th ed). London: Mosby.

Parahoo, K. (1997). Nursing research: principles, process and issues. Hampshire: Macmillan.

Peltzer, K. (2001). Cancer prevention: attitudes among black South African university students. Health RSA, 6(2): 12-17.

Peu, D., Troskie, R. andHattingh, S. (2001). The attitudes of community health nurses towards integration of traditional healers in primary health care in North-West province. Curationis, 24(3): 49-55.

Pillay, A.L. (2002). Rural and urban South African women's awareness of cancers of the breast and cervix. Ethnicity \& Health 7(2): 103-114. 
Polit, D.F. and Hungler, B. (2001). Essentials of nursing research: methods, appraisal and utilisation. (5th ed). Philadelphia: Lippincott.

Polit D.F. and Hungler, B. (2004). Nursing research: principles and methods. (7th ed). Philadelphia: Lippincott.

Potter, P.A. and Perry, A.G. (2001). Fundamentals of nursing. (5th ed). St Louis: Mosby.

Richter, M.S. and Peu, D. (2004). The educational and supportive needs of informal caregivers working at Refentse Clinic, Hammanskraal. Curationis, 27(1) 31-40.

Ross, J.S. and Wilson, J.W. (2001). Anatomy and physiology in health and illness. (9th ed). New York: Churchill Livingstone.

Shai-Mahoko, S.N. (1996). Indigenous healers in the North West Province: a survey of their clinical activities in health care in the rural areas. Curationis, 19(4): 31-34.

Stanhope, M. and Lancaster, J. (2000). Community health nursing. $\left(5^{\text {th }}\right.$ ed). St Louis: Mosby.

Steyn, M. and Muller, D. (2000). Traditional healers and cancer prevention. Curationis, 23(3) 4-11.

Streubert, H.J. and Carpenter, D.R. (1999). Qualitative research in nursing. (2nd ed). Philadelphia: Lippincott, Williams \& Wilkins. 29, 46, 61, 329.

Tshabalala-Msimang, M. (2004). Opening speech given by the Minister of Health at the Conference on Traditional Medicine, Kopanong, 30 March 2004. South Africa. Department of Health. Pretoria: Government Printer.

Vilakazi, H. (2006). 'Conception and Terms of Reference of "The Presidential Project on African Traditional Medicine". Unpublished

Walboomers, J.M., Jacobs, M.V., Manos, M.M., Bosch, F.X., Kummer (according to p. 10) and Shah, K.V. (1999). Human papillomavirus is a necessary cause of invasive cervical cancer. Worldwide Journal of Pathology, 189(1): 12-19.

Walker A.R.P; Michelow, P.M. and Walker, B.F. Cervix cancer in African women in Durban, South Africa. International Journal Of Gynecology \& Obstetrics, 79(1) 45-46.

Westhelmer, R.K. and Lopater, S. (2002). Human sexuality: a psychosocial perspective. Philadelphia: Lippincott.

Xu, W., Towers, A.D., Li, P. and Collet, J.P. (2006). Traditional Chinese medicine in cancer care: perspectives and experiences of patients and professionals in China. European Journal of Cancer Care, 15: 397-403.

Yarbo, C.H., Frogge, M.H. and Goodman, M. (1999). Cancer symptoms management. (2nd ed). USA: Jones \& Bartlett. 